\title{
LOS EXTRANJEROS EN EL DEVENIR CULTURAL DEL MUNDO HELENO
}

\author{
Héctor García Cataldo \\ Pontificia Universidad Católica de Valparaíso. Chile
}

Resumen: En este artículo muestro que el problema de la migración / inmigración, i. e., del extranjero, fue tratado ya por la literatura helena de la época arcaica desde Homero y que ha sido este poeta el que ha instituido la hospitalidad como un rasgo distintivo de la más alta humanidad, un derecho casi inmanente al ethos del hombre.

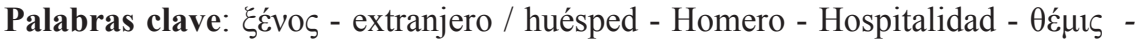
justicia / derecho

\section{FOREIGNERS IN THE CULTURAL DEVELOPMENT OF THE HELLENIC WORLD}

\begin{abstract}
In this article I show that the problem of migration / immigration, i. e., the foreigner, was already treated by the hellenic literature of the Archaic Era since Homer and that it has been this poet who has instituted hospitality as a distinctive feature of the highest humanity, an almost immanent right to the ethos of man.
\end{abstract}

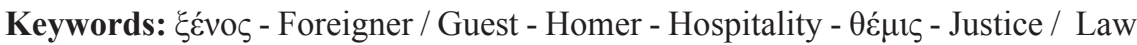

Recibido: 20.12.18 - Aceptado: 20.05.19

Correspondencia: Héctor Edo. García Cataldo.

Email: hector.garcia@pucv.cl; hgcataldo@hotmail.com.

Doctor en Filosofía, por la Pontificia Universidad Católica de Valparaíso (PUCV 2010); Magíster en Historia, con Mención en Historia Europea, por Universidad de Chile (2006); Licenciado en Filología Clásica con Opción Helénica y Latina, por Universidad Católica de Valparaíso (1983). Docente en Instituto de Filosofía PUCV, Universidad de Chile y Universidad de Playa Ancha. 


\section{Introducción ${ }^{1}$}

ué duda cabe que el tema de la migración o del inmigrante
en Chile llegó para quedarse. Se enmarca en un universo
de la llamada globalización, que no es otra cosa que la sustitución de-ideologías totalitarias fenecidas, y la mutación permanente de la doctrina económica neoliberal, que hoy por hoy es útil tanto a derechas empoderadas como a izquierdas desnaturalizadas y sirve de caballo de batalla para la defensa y ataque de unas y otras. Sin duda se trata de un fenómeno universal, que en cifras se traduce en 258 millones de migrantes a nivel mundial ${ }^{2}$ y que en palabras de una autoridad en la temática como lo es NINA NYBER SORENSEN, la migración hoy se ha transformado en una industria ${ }^{3}$; lo mismo ha llegado a ser también la denominada ayuda humanitaria, una industria, esto es, un gran negocio para algunos y, en muchos casos, un negocio que no escatima en la vileza de diversa índole, baste recordar la tan odiada figura del "coyote" en el transporte ilegal hasta el abuso de quienes ofrecen el hospedaje en guetos de hacinamiento inhumano, incluyendo hasta los Estados -como enfatiza la destacada investigadora- que han privatizado muchas funciones de la migración.

En el marco de la libertad del ser humano y especialmente la libertad de movimiento, del desplazamiento hacia otras latitudes, allende causas de coerción, es un estadio connatural al ser humano según hemos aprendido en la Historia de su devenir, inclusive en la construcción de civilizaciones. Una cosa es el natural desplazamiento, pero otra cosa es cuando se transforma en un "negocio" y peor aún cuando se manipula desde intereses ideológico-políticos como resultado ínsito del proyecto globalizador de la postgmodernidad.

¿Qué sentido tiene, en este marco sincrético, plantearse el tema del

1 Ponencia presentada en el II Coloquio Euro-Latino Americano- Inmigrantes, refugiados y desplazados. 25 al 27 de julio de 2018 Pontificia Universidad Católica de Valparaíso, y en el VI Congreso Internacional de Estudios Griegos. Grecia y los otros 17, 18 y 19 de octubre de 2018, Universidad de Chile.

2 Noticias Megavisión, lunes 28 de mayo de 2018. Reportaje a los migrantes chilenos en Inglaterra.

3 CNN CHILE, domingo 17 de junio de 2018. Entrevista a propósito de su estadía en Chile. 
extranjero en el mundo heleno, en los orígenes de la cultura occidental? Dicho de otro modo, desde estas categorías modernas de migración/ inmigración; migrante/inmigrante ¿podemos hallar vestigios de una problemática tal en los orígenes del pensamiento occidental? Y si los hubiere ¿cómo vieron la luz en ese primer pensar y bajo qué formas lingüísticas se manifestaron? ¿qué efectos tuvo -si los tuvo- esa forma originaria y germinal en el devenir de las comunidades en que afloró? Preguntas- problema que orientan esta investigación y que intentaremos abordar desde la historia más genuina desde los orígenes de la cultura occidental.

Una segunda cuestión que no quisiera dejar pasar dice relación con el tema mismo que he propuesto, esto es, el del extranjero o de la migración en el mundo heleno. Se trata de una cuestión de difícil acceso en nuestra cultura, pues ello plantea la posibilidad de una investigación seria y compleja que involucra no sólo la comprensión, la investigación y la reflexión acerca de la cultura helena, sino particularmente porque implica el conocimiento cierto de aquella lengua en que se expresó aquel estadio de pensamiento. Sin embargo, el acceso a este conocimiento ha sido prácticamente imposibilitado desde el momento en que se eliminó de los estudios universitarios la disciplina que cultiva la filológica griega y con ello la reducción de los estudios de la lengua helena en las mallas curriculares de las carreras humanistas, y lo poco y nada que queda de tal enseñanza no permite alcanzar el rigor adecuado para enfrentarse a los textos originales y proponer una investigación profunda en la hermenéutica de esos mismos textos, salvo casos muy excepcionales; y lo que es más preocupante es que se ha privado a los posibles interesados el acceso a dicho conocimiento. De modo que quienes nos dedicamos a esta tarea bizantina de investigar temáticas a partir de la lengua helena debemos hacerlo mirando hacia otras latitudes. En Europa este tema del extranjero -y otros que se van instalando a partir de nuevos conocimientos- en el mundo heleno ha sido un tema largamente estudiado ya a partir de la segunda mitad del siglo pasado. Y en España, a partir de la primera década de este siglo, la problemática del extranjero en Grecia antigua ha sido abordada con una extraordinaria seriedad y profundidad. Prueba de ello es el grupo de investigación interdisciplinario del departamento de Ciencias de la Antigüedad y de la Edad Media de la Universitat Autònoma de Barcelona, liderado por la profesora Rosa-Araceli Santiago Álvarez y que se ha dedicado al estudio de los contactos e interacciones entre poblaciones de distintos orígenes en el marco geográfico, histórico y cultural del mundo 
griego de la Antigüedad, desde el segundo y primer milenio antes de Cristo. Sea esta referencia un sentido reconocimiento a esa extraordinaria labor humanista y cuyos resultados son inspiradores de nuestro trabajo.

Por último, una precisión necesaria respecto del título propuesto. Es de todo punto de vista demasiado ambicioso querer abarcar el devenir completo del desarrollo histórico de los extranjeros a lo largo de la cultura helena; no obstante, es un proyecto de largo aliento. En esta ocasión sólo me remitiré a sus orígenes en la época arcaica y en los textos fundantes de tal época, de modo que lo más apropiado sería titular este artículo: $\boldsymbol{E l}$ extranjero en la época arcaica del mundo heleno: Homero.

\section{1.- Extranjeros y sincretismo étnico}

Al hablar de la época arcaica nos remitimos a los mismos orígenes de la historia helena y por lo que sabemos ya en estos mismos orígenes el extranjero es uno de los componentes fundamentales que originarán lo que serán posteriormente los helenos. Si nos remitimos a preguntarnos quiénes eran los helenos o dicho de otro modo quiénes son los que hoy llamamos helenos, tendremos que abocarnos a sintetizar y decir que en su primer estadio los helenos no son otra cosa que el producto o resultado de un profundo sincretismo étnico, acontecido ya desde la segunda parte del segundo milenio antes de Cristo, sincretismo en que los migrantes son un elemento fundamental. Estos migrantes podemos sintetizarlos para la época entre el 1400 y 1200 a. de C. en los nombres de los aqueos, eolios y de los dorios a los que Heródoto ya en su tiempo identificaba como "helénicos" para diferenciarlo del otro componente étnico de los orígenes, de los jonios, cuya ascendencia la vincula el historiador con los pelasgos autóctonos y de cuyo idioma no puede hablar con seguridad, pero que no obstante califica de "bárbaro", con lo que quería decir simplemente "no helénico" ". Es el período de las invasiones en las islas orientales del mar Egeo, es decir, las costas de Anatolia.

Se ha producido el contacto de estos migrantes invasores con la cultura cretense o minoica, y luego con la micénica, con lo cual ya se produce un primer sincretismo étnico, que en un par de siglos estos migrantes se instalarán en las fronteras del mundo heleno y producirán otro encuentro racial con las poblaciones autóctonas con las que se encontraron como la de los léleges, carios y pelasgos y como bien señala Jardé “Los

4 KITTO, H. D. F., Los griegos. EUDEBA, 1970, p.18-19. 
pelasgos recibieron de los egeo-cretenses los primeros rudimentos de una civilización superior"s. Se trata de lo que se ha dado en llamar la primera colonización, fechada históricamente en los siglos XI y X antes de Cristo, y que Castoriadis refiere como "migración"6. Esta primera oleada de extranjeros migrantes está en la base de lo que será la formación del pueblo heleno. Hay, sin embargo, una segunda oleada de grandes migraciones, la propiamente conocida como segunda colonización, esto es, desde el momento en que los helenos se dispersaron por casi toda la cuenca del Mediterráneo y que comienza en el siglo VIII antes de Cristo, período más o menos coincidente con la fecha de datación de los poemas homéricos; asunto de no menor importancia por las consideraciones que hay que observar a la hora de examinar el contenido de los poemas homéricos, especialmente con respecto a la existencia de la pólis, de lo que no es posible tratar aquí.

Conviene precisar en este punto que al hablar de colonización no debe asociarse el concepto al del establecimiento de un imperio colonial; esto es otra cosa diferente a lo que ha visto el mundo moderno, esto es, la ocupación militar de un espacio territorial, sometido políticamente a la metrópoli y explotado por y para la metrópoli; se trata de la dominación de un Estado, el colonialismo. Esa primera colonización -migración helena- implica la fundación de una colonia como resultado de una empresa "particular" que se debe a la iniciativa de un grupo de ciudadanos: extranjeros migrantes que van produciendo, a su vez, el desplazamiento de poblaciones autóctonas cuando no hay pacto pacífico de ocupación de los territorios. La migración de los siglos oscuros de la Hélade está marcada por esta característica de los desplazamientos, pero en los que en definitiva se fueron imponiendo cuatro grandes etnias, aqueos, jonios, eolios y dorios las que en sucesivos sincretismos temporales terminaron por dar la fisonomía a los helenos. La segunda migración colonizadora ya respondió a otras características, a saber, ya no fue fundamentalmente al asentarse en tierras de cultivo, sino más bien a intereses económicos más definidos (aparición de la riqueza mobiliaria, surgimiento de las grandes ciudades comerciales Mileto y Focea y ciudades industriales como Eubea, Calcis, Corinto, Megara), en muchos casos, a complejas situaciones

5 JARDÉ, A., La formación del pueblo griego. UTEHA, México, 1960, p. 70.

6 CASTORIADIS, C., Lo que hace a Grecia. 1. De Homero a Heráclito. F.C.E. Buenos Aires, 2006, p. 85. 
políticas, a la concepción y a la mala distribución de la propiedad, que desencadena las stáseis, guerras civiles, características del período de la expansión helena de los siglos VIII y VII a. de C., expansión asociada a la inestabilidad de las instituciones políticas y sociales de la mayoría de las ciudades. De esta crisis surgirá la Hélade clásica. Lo cierto es que, en cualquiera de estos casos, especialmente en las ciudades más industriales se requirió de la mano de obra de extranjeros y el pauperismo, en otros casos, como los desclasados se transformaron en extranjeros desplazados. Fenómeno que se da a lo largo de toda la historia de la Hélade y con un interés particular en la época helenística, de la que heredamos hasta hoy el concepto de cosmopolita y por ende de cosmopolitismo (mutatis mutandis, hoy globalización).

\section{2.- La representación del $\xi \xi \dot{\varepsilon} v o \zeta$ en los primeros testimonios literarios de la época arcaica.}

\section{Homero: Ilíada y Odisea}

Los datos más antiguos que hallamos en la cultura occidental acerca del extranjero se encuentran en la Ilíada y la Odisea de Homero y en los Trabajos y días del poeta Hesíodo. ¿Cómo se nos presentan estos vestigios o testimonios en estas obras literarias de la época arcaica de la cultura helena?

Una somera mirada lingüística nos pone de lleno en el problema y pone en evidencia que el tema fue materia de reflexión seria y profunda. Lo que nosotros llamamos "extranjero" los poetas helenos lo llamaron $\xi \dot{\varepsilon} v o \varsigma /$

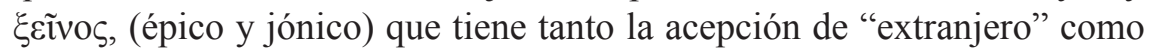
de "huésped", y que está a la base de la creación de un amplio léxico, tanto de substantivos, adjetivos y verbos, a partir de los cuales se devela la institucionalidad que se fue creando en torno a la condición de extranjero como de huésped en el devenir de la cultura. La impronta del lexema $\xi \varepsilon v-$ quedó incorporada a nuestra lengua tanto en su sentido de extranjero como de extraño.

Sin entrar a los detalles y a las interpretaciones del canto guerrero de la Ilíada, llama la atención que en ese contexto de profundos enfrentamientos aparezca el tema de la hospitalidad, la que se manifiesta sin distingos en cualesquiera de los bandos o coaliciones en disputa. Se practica una misma hospitalidad y se respetan ampliamente sus condiciones o reglas. Las élites de los guerreros la practican y viene a constituir una especie de alianza entre 
genos o familias e implica derechos y obligaciones, además, se prolonga (indefinidamente, quizás) en el tiempo. En Ilíada encontramos cuatro o cinco formas lingüísticas que expresan indistintamente tanto la noción de

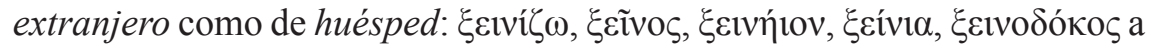
las que desde Odisea podemos añadir la creación del substantivo abstracto

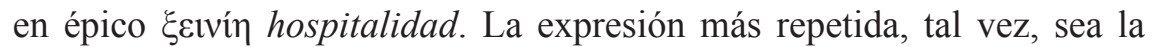
forma verbal del aoristo de $\xi \varepsilon v i \zeta \omega$ en su acepción de recibir a alguien (al extranjero) en calidad de huésped, hospedar. Así, en el canto III cuando Helena va respondiendo a las preguntas del anciano Príamo que desea saber quiénes son los hombres de la coalición enemiga y que Helena conoce porque eran sus anteriores parientes políticos y al describir a Odiseo la interrumpe Anténor, consejero de Príamo, y refiriéndose a Odiseo y a Menelao, quienes habían llegado a Troya en calidad de embajadores, extranjeros, por tanto, para tratar del rescate de Helena, comenta:

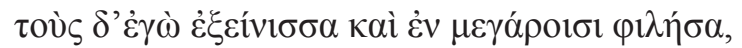

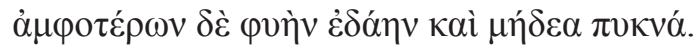

A éstos yo hospedé y acogí amistosamente en el palacio y de ambos conocí el aspecto físico y las sagaces artimañas ${ }^{7}$

Se podría decir que esta forma de expresarse está presente a lo largo de la Ilíada en diversos pasajes y no se trata de un mero formulismo. Lo que importa destacar aquí es que en el verso 207 aparecen unidas dos formas verbales $\dot{\varepsilon} \xi \varepsilon i ́ v i \sigma \sigma \alpha / \varphi i ́ \lambda \eta \sigma \alpha$, que expresan efectivamente la noción de que se recibió al axtranjero en calidad de huésped, pero al mismo tiempo se le manifestó amor, amistad. La semántica del verbo philéo es rica para expresar el amor y sus matices. Las formas en que se manifiesta la recepción del extranjero, el hospedaje propiamente tal, dice relación primero que nada con la alimentación y luego con los regalos, que representan el símbolo del pacto recíproco del vínculo que genera la hospitalidad. Por el relato de Patroclo en el Canto XI nos enteramos que Aquiles:

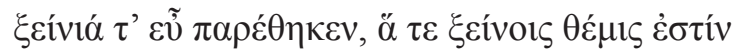

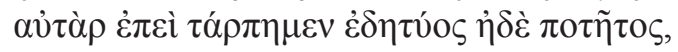

7 Il. III, 207-208 
ofreció esplédidamente regalos de hospitalidad, que para los extranjeros son themis.

Después de deleitarnos con la comida y la bebida, ${ }^{8}$

Qué significa aquí en este pasaje y otros que los Ģívió dones de hospitalidad son themis?. Si entendemos esta palabra como un orden establecido desde siempre bajo carácter divino, entonces se estaría diciendo que los asuntos relativos a los extranjeros en tanto que un servicio de hospitalidad tienen un carácter inveterado en el tiempo y no se sabe desde cuándo se estableció esto y, por tanto, ya se trata de una costumbre, un orden establecido de antemano para los extranjeros. Por otra parte, si entendemos themis como "justicia", lo que se querría resaltar, entonces, es que la comida y la bebida es una cuestión de justicia (divina) afrecerla a los extranjeros. No estamos todavía en el ámbito propiamente del derecho, pero hay un guiño, por así decirlo, hacia ese ámbito, máxime si no se pone en discusión (y con Castoriadis) que Homero ya conoce el incipiente sentido político de la pólis, de modo que lo que ya plantea Homero es que se trata de una cuestión "legítima", es lo que se "debe" a los extranjeros y es propio del tratamiento hospitalario. Un pasaje significativo lo hallamos en Odisea Canto XXIV en el diálogo que sostienen Odiseo, presentándose como un extranjero, y su padre Laertes que aún no lo ha reconocido:

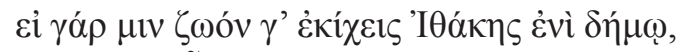

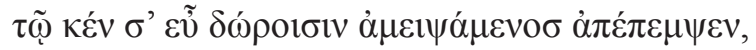

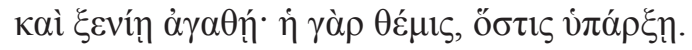

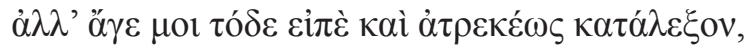

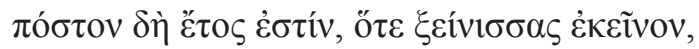

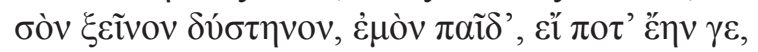
$\delta$ $\sigma \mu \mathrm{o} \tau \mathrm{ov}$

Pues, si lo encontraras vivo en el demo de Ítaca, bien recompensado por él con regalos te despediría y con buen hospedaje: porque hay themis, quienquiera que se presente.

Pero, ¡vamos! dime esto y exprésalo francamente, ¿Cuántos años han pasado ya desde que hospedaste a aquél

8 XI, 79-80. 
a tu huésped/extranjero desgraciado, a mi hijo, si por ese entonces era infortunado? ${ }^{9}$

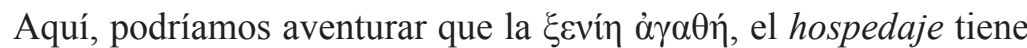
el carácter de ser ya casi una institución, pues es una consecuencia de que haya themis, esto es, que cualquier forastero que lo requiera como es debido recibirá una atención agathé, buena; y que en el momento de su

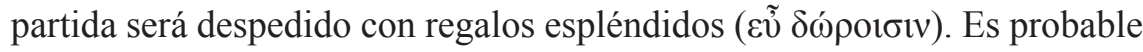
que este pasaje como la Odisea en su conjunto muestre un estadio cultural ya más avanzado con respecto a la Ilíada, pero sobre esta problemática no es pertinente ahondar aquí.

Volviendo a Ilíada y particularmente a la referencia de Príamo y Helena, que para el rey ella no es responsable de la guerra, no obstante, ella y su esposo original Menelao recibieron en su momento al extranjero troyano Alejandro/Paris como huésped en su palacio. Ocasión en que Alejandro violenta y transgrede precisamente no sólo la institución "ancestral" de la hospitalidad, sino también resquebraja el vínculo ético de la amistad que en ella se establece recíprocamente en el tiempo. Las consecuencias de tal violación serán terribles y están en la base del argumento mismo de la Ilíada:

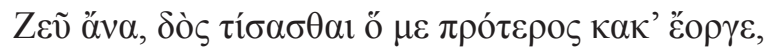

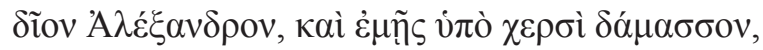

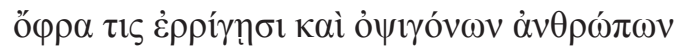

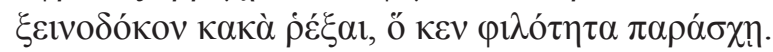

¡Zeus soberano! Concédeme vengarme del que antes ha hecho mal, del divino Alejandro, y hazlo sucumbir bajo mis manos, para que también los hombres venideros se estremezcan de hacer mal al que aloje a un huésped y le ofrezca amistad $^{10}$

9 Od. XXIV, 284-290.

10 Il. III, 351-354. 
La traición requiere expiarse a través de la venganza, que es la fuerza temática y argumentativa de la Ilíada, el canto a la ira vengativa. Pero aquí lo central radica en hacer pagar la traición que se comete contra la persona que da hospedaje al extranjero, porque no sólo da tal servicio, sino porque en tanto que "hospedador" ofrece algo más significativo aún: la amistad, $\varphi \imath \lambda o ́ \tau \eta \varsigma$, derivado de la misma raíz del verbo philéo. Homero ha creado un concepto nuevo, componiéndolo con la misma palabra

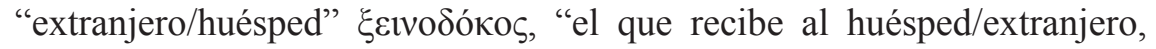
el anfitrión, el hospedante/hospedador", término que se repetirá varias veces en Odisea y que en el devenir del desarrollo político de la cultura helena cobrará relevancia mayor. La invocación de Menelao implica que la venganza debe ser ejemplificadora, porque tanto la hospitalidad como la amistad representan un valor de humanidad siempre y para siempre ${ }^{11}$; el protector invocado es por lo mismo Zeus, quien es calificado con el epíteto de $\xi$ cívios, esto es, "protector de los derechos de hospitalidad, hospitalario" y que castiga a quien no respeta el cumplimiento de la themis de todo extranjero.

Un largo pasaje de Ilíada que merecería un tratamiento más detallado se halla en el Canto VI cuando están a punto de enfrentarse a muerte Glauco, un aliado troyano, y Diomedes por parte de los helenos, pero que antes del combate quieren saber ambos sus orígenes, algo muy propio de la narrativa homérica. En ese diálogo descubren que ambos están unidos desde hace a lo menos tres generaciones atrás por los lazos de la hospitalidad. Así como en el pasado sus ancestros intercambiaron

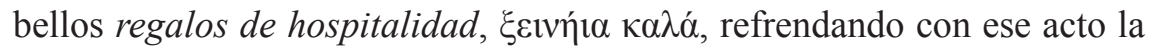
reciprocidad vinculante para la condición de extranjero/huésped, según sea para uno u otro de los miembros de la familia, así también ahora Diomedes propone a Glauco que intercambien sus armas para que "también éstos se enteren de que nos jactamos de ser huéspedes por nuestros padres" ${ }^{12}$. La interpretación corriente que se ha dado a este intercambio de armas ha estado vinculada a la ate o infatuación que envía Zeus como pérdida momoentánea de la razón, pues las armas de Glauco eran muy superiores porque eran de oro; las de Diomedes, de bronce. Visto el pasaje desde esta perspectiva me parece muy acertado el comentario de la profesora RosaAraceli Santiago Álvarez, que destaca que no importa tanto aquí el valor

11 Cfr. con Il. XIII, 623-627.

12 Il. VI, 230-231.

98 
material de las armas,sino "el vínculo que representaban. La fuerza de ese vínculo está por encima de las leyes de la guerra, [...] Constituye asimismo motivo social de orgullo"13.

La Odisea en su conjunto temático trata la problemática del xénos en tanto que extranjero con mucha más atención, por decirlo así, toda vez que su personaje principal en su perigrinaje se presenta en calidad de extranjero y, a la vez, es atendido como huésped, relación que estrecha vínculos. Así, en el último canto cuando Odiseo se hace pasar por el extranjero Epérito, procedente de Alibante, en el relato que hace a su padre Laertes se autodescribe como quien había hospedado a muchos extranjeros de tierras lejanas y en tanto que Epérito había hospedado a Odiseo y que en el momento de su partida lo había apoyado gustosamente y añade este comentario:

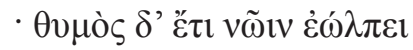

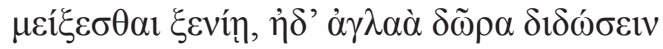

y el sentir de los dos aun más tenía la esperanza

que nos uniríamos por la hospitalidad y que nos habríamos de dar espléndidos regalos ${ }^{14}$.

Desde esta perspectiva, en ambos poemas se ha esbozado la idea que la recepción de extranjeros, según las normas de respeto por las que un extranjero solicita la hospitalidad, establece vínculos y que esos vínculos quedan refrendados no por leyes en el sentido estricto del derecho, sino por recursos materiales en el sentido más amplio, expresado por la palabra $\delta \tilde{\omega} \rho \alpha$, en plural regalos, y por la palabra $\xi \varepsilon i ́ v i \alpha$, también en plural que son los regalos hospitalarios que se dan al huésped por parte de su hospedador, que consisten generalmente en comida y bebida, que es lo que constituye un indispensable acto de themis humanitaria -podríamos decir-, después de esto vienen el diálogo y las preguntas acerca de la procedencia, el genos $\mathrm{y}$ las intenciones o actividades por las que se ha viajado: si se ha viajado

13 Véase "La polaridad «huésped» / «extranjero» en los poemas homéricos", en Faventia Supplementa 2. Contacto de poblaciones y extranjería en el mundo griego antiguo. Estudio de fuentes. Bellaterra, Universitat Autònoma de Barcelona, 2013, p. 35.

14 Od. XXIV, 313-314. 
por motivo de comercio o piratería ${ }^{15}$. Esto nos habla que ya para la época arcaica ambas eran actividades en apogeo y que la actividad comercial por mar hacía que llegaran muchos extranjeros de tierras muy lejanas.

Si en la Ilíada el xénos se vincula más a las élites y tenemos menos información de la sociedad más general, en la Odisea aparece esta información y como ha dicho Bowra aparecen los seres humildes y por tanto en la institución de la hospitalidad, ésta no sólo se da en las clases altas, sino que cualquiera y de cualquier condición social estaba en condiciones de solicitarla y recibir las atenciones que la sabiduría ancestral había considerado como themis. Al huésped no le podía ocurrir nada negativo, ningún oprobio ni menos violentarlo, porque se constituía en motivo de vergüenza y condena en el demos ${ }^{16}$; cuando llega Odiseo como extranjero, irreconocible, y se encuentra con el porquero Eumeo, éste lo recibe con todo esmero y cuidado; Odiseo le agradece tanta atención, Eumeo le hace este comentario:

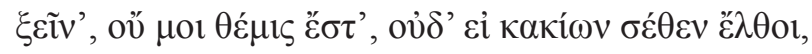

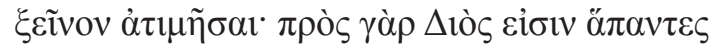

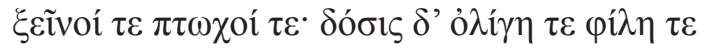

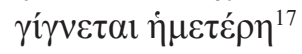

¡Oh extranjero! No me está permitido, ni aunque [uno] llegase peor que tú, que yo desestimara a un extranjero, porque de Zeus proceden todos tanto extranjeros como mendigos:

y una poca donación nuestra es amada.

La asociación entre el extranjero y el pobre no es gratuita. Ambos comparten la misma condición: su condición de suplicantes de mendicantes y cualquiera fuera su condición y estatus social estaban protegidos por la

15 Referir los pasajes más relevantes y retomar análisis de algunos: Od. III, 71$74,301 \mathrm{ss}$; IX, 252-255 etc. La piratería fue una práctica constante de los mismos griegos en el extranjero Od. III, 105-106; IV, 81-85.

16 Od. XVIII, 223-225.

17 Od. XIV, 56-59. 
divinidad de Zeus. En palabras de Alcínoo: “Extranjero y suplicante, para cualquier varón que muestre un mínimo de sensatez, son equiparables a un hermano"18. Los poetas líricos posteriores ahondarán en esta problemática, señalándo a la pobreza, como una de las cosas más terrible y aborrecible a la vez ${ }^{19}$. Una buena hospitalidad no hace distingos de clase social

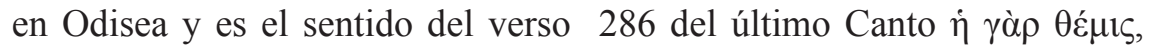
ő $\tau \imath \varsigma ~ ن ં \alpha ́ \rho \xi \eta$, porque existe una justicia divina, quienquiera que se haya presentado. En la evolución del imaginario de pólis hallaremos que esta concepción ancestral inveterada de la hospitalidad será asumida como rol y responsabilidad política y se incorporará entre las funciones de la institucionalidad como tal.

Atenciones especiales merecerían, por ejemplo, los Cantos octavo y siguientes, los relatos de Odiseo en el palacio de Alcínoo, especialmente el relato del encuentro con el Cíclope. Por ahora sólo señalaremos que en este relato la problemática de la hospitalidad hacia los extranjeros apunta al más alto sentido al que debe aspirar la pólis civilizada. Demarca el límite entre la civilización y la barbarie, la isla de los Cíclopes es un mundo sin themis precisamente y sin agorai boulefóroi, un mundo individualista que no conoce la existencia de un "otro"; existe la violencia, son hybristaí. Al llegar a esta isla, Homero hace que Odiseo se pregunte si serán "hospitalarios" y crea un nuevo concepto a partir de "extranjero/ huésped", el de $\varphi \imath \lambda o ́ \xi \varepsilon ı v o s$, literalmente amigo del extranjero ${ }^{20}$ y con ello instala el germen de un nuevo imaginario para el devenir político y cultural del desarrollo de las relaciones en pólis. Una atención más profunda a este relato como al del último Canto nos llevaría a sostener que Homero anticipa un imaginario de reglamentación institucional de las relaciones sociales que podríamos llamar internacionales, pues se trata de relaciones inter poleis, que independientes, cada una constituirá lo que llamamos "Ciudad-Estado", pólis in stricto sensu.

18 Od. VIII, 546s:

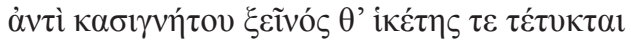

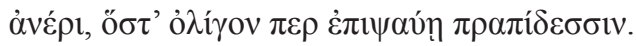

Cfr. además con Od. IX, 266-271.

19 Véase: Tirteo de Esparta. En Edmonds I, 10 (6+7 D).

20 Od. IX, 176. 


\section{A modo de conclusión}

Las notas precedentes no son más que indicadores significativos que el tema del extranjero y el problema de la hospitalidad fueron tratados por la cultura helena arcaica desde sus mismos fundamentos.

Hay una notable diferencia con los acontecimientos que al respecto vemos en nuestro mundo en que la problemática de los refugiados, desplazados o simplemente inmigrantes ha venido a desembocar en un negocio lucrativo y sin escrúpulos para que quienes lo han puesto en práctica desde las esferas mismas del poder político tal como lo hemos visto de facto en nuestra prensa nacional en los primeros meses del presente año (2019), en que personeros vinculados a un Municipio en particular están involucrados en el tráfico de inmigrantes a territorio nacional.

Respecto del mundo heleno hemos podido constatar que semánticamente con una sola palabra se aludía a dos conceptos aparentemente distantos, pero que en el fondo forman parte, esencialmente, de una misma realidad: $\xi \dot{c} v o \varsigma$ significa extranjero, pero al mismo tiempo puede significa huésped; cuya etimología ha permanecido hasta nuestros días como en xenofilia y xenofobia y sus respectivas formas adjetivales, en las que ha primado el sentido de extranjero. Llama la atención que en Homero, tanto en Ilíada como en Odisea se expresen ambas realidades, incluso más, que ya se halla el sentido del abstracto hospitalidad, referido indistintamente a cualesquiera de los bandos en disputa ( en la guerra de Troya): indiferenciadamente se practica como un gesto de notable $\varphi \imath \lambda i ́ \alpha$ (de amor): comida y regalos son la expresión máxima de la hospitalidad y el sello indiscutido de la amistad; siendo los regalos hospitalarios la expresión máxima de un "derecho" inveterado del que no se tiene noción de sus inicios, porque está en el ethos de los hombres y representan la themis para cualquier extranjero, quienquiera que éste sea y, por tanto, la hospitalidad va tomando el rango de un derecho instituido y de carácter inviolable, máximo vínculo ético de la amistad. De ahí que la transgresión a esta themis sea al mismo tiempo la transgresión a la amistad incondicional. Por eso Zeus es su garante, es el protector de los derechos de hospitalidad,

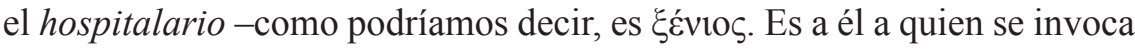
en el acto de vengaza cuando esa themis ha sido violentada. Por último, bien vale la pena destacar que en la creación homérica del $\varphi \imath \lambda o ́ \xi \varepsilon v v o s$, es decir, del amor al extranjero, el poeta ha instalado un imaginario que es rango distintivo de las relaciones humanas que comienzan a tomar forma en el incipiente devenir de la pólis. 


\section{Referencias bibliográficas}

\section{Fuentes-Ediciones}

HOMER (1978). The Iliad. Traducción de A. T. Murray. Harvard University Press: London.

HOMERI (1839). Odyssea. Nova editio stereotypa. Tomus I y II. Lipsiae.

HOMERO (2008). Ilíada. Versión de Rubén Bonifaz Nuño. Bibliotheca Scriptorum Graecorum et Romanorum Mexicana. Edición bilingüe. Universidad Nacional Autónoma de México.

HOMERO (2000). Odisea. Traducción de José Manuel Pabón. Editorial Gredos: Madrid.

\section{Complementaria}

CASTORIADIS, C. (2006). Lo que hace a Grecia. 1. De Homero a Heráclito. F.C.E. : Buenos Aires.

GARCÍA-BILBAO, P. A. (2012). "Migraciones forzosas en el mundo clásico: Plutarco y la construcción social de la identidad", en BARATARIA. Revista Castellano-Manchega de Ciencias sociales No 14, pp. 157-170.

GLOTZ. G. (1957). La ciudad griega. UTHEA: México.

IRIARTE, A. (2007). "La institución de la Xenía: pactos y acogida en la antigua Grecia”, en Gerión 2007, Vol. Extra, pp. 197-206.

JARDÉ, A. (1960). La formación del pueblo griego. UTEHA: México.

KITTO, H. D. F. (1970). Los griegos. EUDEBA: Buenos Aires.

PIÑOL, A. (2015). El extranjero en la Grecia arcaica: acceso a la tierra y a la justicia. Tesis doctoral. Universitat Autònoma de Barcelona.

SANTIAGO ÁLVAREZ, R-A. (2013). "La polaridad «huésped» / «extranjero» en los Poemas Homéricos", en Faventia Supplementa 2. Contacto de poblaciones y extranjería en el mundo griego antiguo. Estudio de fuentes. Bellaterra, Universitat Autònoma de Barcelona. 